\title{
Impacts of the socio-political instability in Hong Kong on university students' learning experience
}

\section{Henry T. Y. Fung}

Department of Communication Studies, Hong Kong Baptist University, Hong Kong.

\begin{abstract}
Since the Anti-Extradition Law Amendment Bill Movement in 2019, Hong Kong has entered an era of socio-political instability. The conflict between student protesters and the government has become increasingly intense, whereas several universities even became the battlefield of the protest and were abruptly shut down in November 2019. To add fuel to the fire, the outbreak of the COVID-19 pandemic in early 2020 has prompted all universities in the territory to suspend all face-to-face classes and activities for two semesters consecutively. All these have impacted university students in Hong Kong socially, academically and psychologically.

In light of this, this study aims to explore the ways in which the learning experience of university students in Hong Kong has been impacted by the socio-political challenges. Through conducting a mixed-methods study at a public university in Hong Kong, it was found that university students have a high perceived level of stress, high political involvements, unsatisfactory learning experience and poor learning motivation under this socio-political backdrop. It is hoped that this study can provide informed insights for teachers to understand students' burdens, stresses, and emotional instability associated with socio-political unrest.
\end{abstract}

Keywords: University students; socio-political instability; learning experience, perceived stress. 


\section{Introduction}

Hong Kong, a former British colony, was handed over to China peacefully in 1997 following the "one country, two systems" principle preserving its capitalist system and the way of life for 50 years. Since Mid-2019, however, the Anti-Extradition Law Amendment Bill (AntiELAB) Movement has rocked the city with fragmented, decentralized and radicalized protests where many university students have been involved in these events demanding institutional reforms, investigation into alleged police brutality, and universal suffrage for Hong Kong people (Choi, 2020). Radical protesters often adopted disruptive and violent tactics to achieve the movement goals, while several universities were occupied by protesters and turned into a battlefield between student activists and riot police (Pang \& Smith, 2019). All on-campus classes, exams, and research activities were forced to shut down and were switched to online mode as a contingency measure.

Entering January 2020, the outbreak of the COVID-19 pandemic called off the street protests and quieted every place in Hong Kong. All universities in Hong Kong suspended their oncampus activities and switched to online mode again for the entire Spring semester of which students are the ones who suffered a lot from the social movements and pandemic. On the other hand, since university students also played a major role in the Anti-ELAB Movement (Lee, 2020), many students might feel stressed, anxious and/or depressed when faced with uncertainties and personal risks, which could result in lower motivation to study and poor academic performance (Hope, Velez, Offidani-Bertrand, Keels \& Durkee, 2018).

Despite the research significance of learning more about university students' learning experience under socio-political instability, very little is known in this area. This study is one of the pioneers in Hong Kong to fill in the research gap by investigating how university students perceive their learning experience amid the social movement in 2019 and the outbreak of the COVID-19 pandemic in 2020.

This study is significant for at least three reasons. First, it helps narrow the research gap on the impact of social unrest on university students' learning and academic achievement, which aligns with the growing literature investigating the rise of student activism in Hong Kong (Cheng, 2016; Cheng \& Chan, 2017). Second, it provides insights for teachers and senior management to implement interventions and policies that alleviate students' burdens, stresses, and emotional instability associated with social unrest (Gershenson \& Hayes, 2016). Third, in an era of uncertainties, it is believed that the findings gathered in Hong Kong can be applicable or even transferable in dealing with other countries' learning problems induced by precarious political and social difficulties. 


\section{Theoretical Framework}

Hong Kong university students' learning experience under the backdrop of socio-political instability is best investigated and interpreted through the lens of Bronfenbrenner's (1979) Nested Ecological System Theory (EST), which views a person's development as taking place within a set of environmental systems interacting with one another. According to Bronfenbrenner (1979), human development is highly complex, individuals and their environments are interrelated and mutually shaping in five spheres, namely the microsystem, mesosystem, exosystem, macrosystem, and chronosystem. The quality of interactions and resources embedded in an individual's environment shapes one's potential for success or failure (Ceci \& Hembrooke, 2005). The model is very useful to understand the factors coinfluencing students at different levels. The nested diagram in Figure 1 represents the ecological systems in which the university students in Hong Kong are situated.

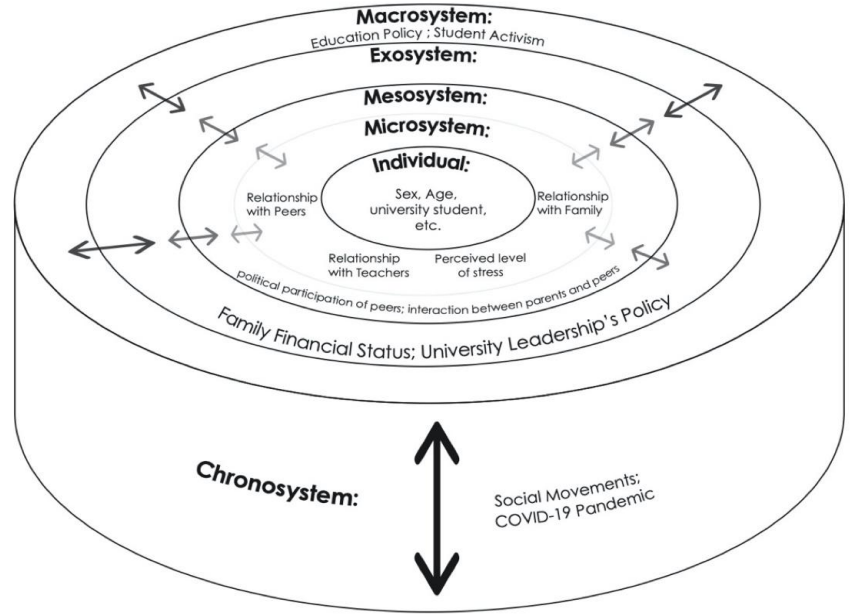

Figure 1. The Nested Ecological System Model of Hong Kong University Students' Learning Experience Under Socio-Political Unrest.

Microsystem refers to the settings that individuals directly interact within their daily lives. Home, university, library, workplace, and neighborhoods are typical contexts for university students to engage with their family, peers, teachers and supervisors. It is in this environmental layer that students perform their daily activities, fulfill their social roles, and develop their interpersonal relationships, hence this is the most direct, interactive and influential level of the theory (Bronfenbrenner, 1994). During the socio-political instability, the most immediate microsystem factors affecting students' learning experience include students' perceived stress level, relationship with teachers, interactions with peers and peers' level of political participation. All these factors influence and are influenced by the learning experience of university students. 
For Mesosystem, it is a "system of microsystems" (Bronfenbrenner, 1977, p. 514). It comprises the interactions between the different parts of a person's microsystem. In other words, this is where a student's microsystems interconnected and assert influence upon one another. According to Bronfenbrenner (1979), development is a result of interactions between the complex webs of microsystems. The school-family relationship can have both positive and negative impacts on a high school learner (Leonard, 2011). On the other hand, if parents both work out of home and disengage from their children's education, both parents and children report more stress which can affect their work and academic performance (Acs \& Nelson, 2003; Hanson \& Lynch, 2004). It is believed similar findings will also be found in the undergraduate students who are dependent on their parents.

And for Exosystem, it refers to the larger social settings that are external to the individual but would impact, delimit, or foster the development of the individual. (Bronfenbrenner, 1977). One typical relevant example will be the work lives of the parents, which directly relates to household resources and parental stress, can influence family dynamics and subsequently impacts the life of the child (Subotnik, Olszewski-Kubilius \& Arnold, 2003). In the world of a university student, exosystem may also include the family financial status, and university leadership and the Education Bureau which are similarly distant from his/her daily experience but powerful in shaping the overall learning experience of the student.

Furthermore, Macrosystem is the wider socio-cultural environment that includes the micro, meso, and ecosystems. This layer comprises values, beliefs, laws and ideologies that underlie a particular culture and are shaped by all levels of the ecological system (Bronfenbrenner, 2005). As culture can be passed from one generation to the other, the dominant cultural practices and belief systems of parents and teachers on the notion of success can directly affect how the children organize their daily routines to achieve their goals, thereby also influencing their learning experience and academic performance (Amatea, 2009). Apart from that, macrosystem can be interpreted as the overall condition of the society that impacts the structure and functioning of individuals' social-ecological system (Stokols, Misra, Runnerstrom \& Hipp, 2009).

Last but not least, Chronosystem is the outermost layer pertaining to the environmental events and transitions in life. It involves transitions in life and sociohistorical events that shape how a person or society works (Bronfenbrenner, 2005). Undeniably, the recent ELAB social movements and the outbreak of COVID-19 pandemic in Hong Kong have disrupted the normal social ecology of every student. It is foreseeable that the devastating consequences brought by this socio-political turmoil would alter students' learning experience and their conceptions of life value. 


\section{Methodology and Research Design}

The objective of this study is to examine how university students perceive their learning experience under socio-political instability in Hong Kong, and whether such an unfavorable environment would impact their perceived level of stress and academic performance. The focus is to examine the factors that affect students physically, emotionally and academically. Specifically, there are three research questions guiding this study:

(1) How do Hong Kong undergraduate students perceive their learning experience under socio-political instability from 2019 to 2020 ?

(2) What is the perceived stress level of undergraduate students in Hong Kong under sociopolitical instability?

(3) What are the levels of political participation of undergraduate students in Hong Kong?

This study is conducted after the Anti-Extradition Law Social Movement in 2019 and during the outbreak of COVID-19 pandemic in 2020. To address the above research questions, a mixed-methods methodology consisting of an online questionnaire and semi-structured interviews was carried out by the researcher from August to September 2020 at a public liberal arts university in Hong Kong. The purpose of having a mixed-methods study is to gain a comprehensive view of the impacts of socio-political instability on university students' learning experience. The participants of the questionnaire study included 59 university students aged 18 and above enrolled at a public university in Hong Kong. As for the online interviews, participants are six Year 3 and Year 4 student representatives who are in a leadership position within a student society or organization. Participants may have different majors, but all have been enrolled at the University for at least a year. No incoming freshmen are being recruited.

It is important to understand the context of this research study in a more detailed fashion. The online questionnaire was collected between 7th and 14th August 2020 when Hong Kong was experiencing the third wave of the COVID-19 pandemic where the total number of infections exceeded 4000 cases. Also, this study was conducted after the implementation of the National Security Law on 30th June 2020 which was unpopularly viewed by the critics as an erosion of the city's freedom of speech. Specifically, participants of the online questionnaire were recruited through a convenience sampling technique by sending an email invitation to all his former students. As for the semi-structured interviews, a purposeful sampling method was used, where the researcher first generated a list of potential participants whom he knows are 18 or above and is/was a committee member of a student society, union, hall of residence, or university senate. These criteria allow the researcher to find active student members of the university community, who have frequent engagement with students, faculty members, staff, alumni and/or university leadership and have a more holistic picture of the changes brought 
by the socio-political instability on university students' learning experience. This can ensure that the key informants have a unique perspective and background knowledge related to the study (Etikan, Musa \& Alkassim, 2016).

\section{Data Analysis}

Among the data collected by the mixed-methods research, the findings could be divided into four important parts: High perceived stress level, high political involvement of students, unsatisfactory learning experience and poor learning motivation.

\subsection{High Perceived Stress Level}

In this study, the 14-item Perceived Stress Scale (Cohen et al., 1983) was used to evaluate the extent to which university students in Hong Kong consider environments in their life to be stressful. This scale comprises seven items worded negatively, and seven items worded positively. Participants need to rate the degree of their general agreement with these 14 items on a five-point Likert scale ranging from 0 (never) to 4 (very often), and their responses are then totaled, with higher scores indicating a greater level of perceived stress. Cohen and his colleagues (1983) found high internal consistency reliability $(\alpha=.84$ to .86$)$ in college freshmen, introductory psychology students, and individuals enrolled in a smoking cessation program. According to Cohen, Kamarck and Mermelstein (1983), the results of the scores can be compared with scores pre-determined for the questionnaire. For instance, scores between 0-28 can be viewed as a low level of perceived stress, 29-42 means moderate, while scores above 43 indicate a high degree of perceived stress.

One of the objectives of this study is to find out if students suffer from a high perceived level of stress under the socio-political instability. Among the 59 participants, 48 valid responses were collected for measuring their stress level. By comparing the aggregated mean scores (i.e. 44.8) with Cohen's (1994) reference scores, it was found that Hong Kong university students had a high degree of perceived stress level. However, it remained unknown what constituted such a high level of stress of students. Therefore, six semi-structured interviews were carried out to further comprehend the data. It was found that the sudden suspension of face-to-face classes, worries of having poorer academic results under online learning, social and political tensions during the social movements, and uncertainties of the career prospects after graduation are common stressors reported by the students.

\subsection{High political involvement of students}

In the online questionnaire, participants were being asked to indicate if they have engaged in any forms of political actions in the past. Sample items include: "Did you go to vote in the legislative district election?", "Have you ever taken part in any class boycott activity?", and "Have you ever participated in any rally or demonstration?". Furthermore, participants 
assessed their political activeness on a five-point Likert scale, ranging from "apolitical" to "politically very active". Also, they needed to indicate how much time they spent on acquiring political information on a daily basis and to rate how often they discuss politics with significant others.

As expected from the literature, university students in Hong Kong show a high degree of political involvement. Approximately $73 \%$ of the respondents went to vote in the legislative district election, although only $9 \%$ of the students indicated that they are affiliated with a political group/party. More than $63 \%$ of the respondents signed a petition in the last 6 months for supporting a political idea. And more significantly, over $68 \%$ of the students claimed that they have participated in a rally or demonstration before. These findings showed that students are involved in both conventional and unconventional forms of political engagement.

\subsection{Unsatisfactory learning experience}

To investigate how university students perceive their learning experience amid sociopolitical instability, open-ended questions were used in the online interviews to gain insights into students' accounts of their learning experience. Participants were being asked in both the online questionnaire and semi-structured interviews to elucidate how their learning experience has been affected since the social movement in 2019.

By analyzing the responses of the two open-ended questions and the interview data, it was found that the majority of the respondents revealed that their learning experience in the academic year of 2019 and 2020 was unsatisfactory. Many of them complained about online learning under campus closures. For example, one student pointed out three problems of having classes online, including "not active", "inconvenience in taking online exams", and "feeling helpless when encountering technical problems". Also, several students blamed teachers' incompetence in delivering the course content effectively in a virtual environment. For instance, there were concerns about "cancellations of the lessons", "lack of engagement between teachers and students", as well as "uncertainties about the grading and assessment arrangement". These findings align with the arguments of other studies that the effectiveness of learning emergently online relies on teachers' competencies of online teaching and instructional design. However, a few students said they enjoyed the learning experience because they could enjoy more leisure time than before.

\subsection{Poor learning motivation}

This study used self-reported cumulative grade point average (CGPA) as the key measure of academic performance. This can ensure the anonymity of each participant as no identifiable personal information such as name, academic major and transcript are gathered. To better understand the potential challenges faced, participants are being asked to rate ten different factors (e.g.. political tensions, class suspensions, academic stress, student-teacher 
relationship) that may affect their academic performance at school in a five-point Likert scale, ranging from "Not at all" to "Extremely".

Among all the respondents, 31 of them self-reported that their CGPA is 3.0 or above in the Spring 2020 semester, meaning that they are the high achievers. However, when asked about their perceptions of how socio-political instability affects their academic performance, many of them agreed that the unfavorable social conditions have negatively affected their learning motivation. In particular, two students explicitly mentioned that their attention was distracted by studying remotely at home. Yet, a few students did not agree that their learning has been adversely affected as they could easily raise questions by email or making online calls with professors during the pandemic. Also, they had more time to self-study under the class suspension. Again, further investigation is needed by conducting semi-structured interviews with student representatives.

\section{Conclusion}

This research study aims to explore the ways in which the learning experience of university students in Hong Kong has been impacted by the socio-political challenges since 2019. By conducting a mixed-methods research, it was found that university students had a high degree of perceived stress and political involvement in the years of 2019 and 2020. Regarding their learning experience, many of them claimed that they had a bad experience learning remotely at home. The overall learning experience was unsatisfactory because of the incompetence of teachers, lack of technical support, and poor interactions among peers and teachers. Despite the significance of the findings, this study was constrained by the low sample size drawn from one university in Hong Kong, hence the representativeness of the findings is relatively low. Moreover, the generalizability of the results is also limited by the convenience sampling method employed to collect the online survey data. As the pandemic continues, future studies should be done in a city-wide scale to further examine the impacts of socio-political unrest on university students, and to formulate informed interventions to improve their overall learning experience.

\section{References}

Acs, G., \& Nelson, S. (2003). Changes in family structure and child well-being: Evidence from the 2002 National Survey of America's Families. DC: Urban Institute.

Amatea, E. (2009). Building culturally responsive family-school relationships. Upper Saddle River, NJ: Pearson Education

BBC News. (2019, October 23). Hong Kong formally scraps extradition bill that sparked protests. Retrieved from: https://www.bbc.com/news/world-asia-china-50150853 
Bronfenbrenner, U. (1977). Lewinian space and ecological substance. Journal of Social Issues, 33(4), 199-212.

Bronfenbrenner, U. (1979). The ecology of human development. Harvard university press.

Bronfenbrenner, U. (1994). Ecological models of human development. Readings on the development of children, 2(1), 37-43.

Bronfenbrenner, U. (2005). Making human beings human: Bioecological perspectives on human development. CA: Sage.

Ceci, S. J., \& Hembrooke, H. A. (2005). A bioecological model of intellectual development. In P. Moen, G. H. Elder, \& K. Luscher (Eds.), Examining lives in context: Perspectives on the ecology of human development, (pp. 303-345). Washington, DC: American Psychological Association.

Cheng, E. (2016). Street politics in a hybrid regime: The diffusion of political activism in post-colonial Hong Kong. The China Quarterly, 226, 383-406.

Cheng, E. W., \& Chan, W.-Y. (2017). Explaining spontaneous occupation: antecedents, contingencies and spaces in the Umbrella Movement. Social Movement Studies, 16(2), 222-239.

Choi, S. Y. (2020). When protests and daily life converge: The spaces and people of Hong Kong's anti-extradition movement. Critique of Anthropology, 40(2), 277-282.

Cohen, S., Kamarck, T., \& Mermelstein, R. (1983). A global measure of perceived stress. Journal of Health and Social Behavior, 24, 385-396.

Cohen, S., Kamarck, T., \& Mermelstein, R. (1994). Perceived stress scale. Measuring stress: A guide for health and social scientists, 10.

Etikan, I., Musa, S. A., \& Alkassim, R. S. (2016). Comparison of convenience sampling and purposive sampling. American journal of theoretical and applied statistics, 5(1), 1-4.

Gershenson, S. \& Hayes, M. S. (2016). Short-run externalities of civic unrest: Evidence from Ferguson, Missouri. In: IZA Discussion Papers

Hanson, M. J., \& Lynch, E. W. (2004). Understanding families. Approaches to Diversity, Disability, and Risk. Baltimore: Paul H Brookes Publishing Co.

Hope, E. C., Velez, G., Offidani-Bertrand, C., Keels, M., \& Durkee, M. I. (2018). Political activism and mental health among Black and Latinx college students. Cultural Diversity and Ethnic Minority Psychology, 24(1), 26-39. doi:10.1037/cdp0000144

Lee, L. F. (2020). Solidarity in the anti-extradition bill movement in Hong Kong. Critical Asian Studies, 52(1): 18-32.

Leonard, J. (2011). Using Bronfenbrenner's ecological theory to understand community partnerships: A historical case study of one urban high school. Urban Education, 46(5), 987-1010.

Pang, J. \& Smith, J. (2019, Nov 12). Hong Kong universities become 'battlefields' as citywide violence spreads. Reuters Hong Kong. Retrieved from https://www.reuters.com/article/us-hongkong-protests/hong-kong-universities-becomebattlefields-as-citywide-violence-spreads-idUSKBN1XM00X 
Stokols, D., Misra, S., Runnerstrom, M. G., \& Hipp, J. A. (2009). Psychology in an age of ecological crisis: From personal angst to collective action. American Psychologist, 64(3), 181.

Subotnik, R. F., Olszewski-Kubilius, P., \& Arnold, K. D. (2003). Beyond Bloom: Revisiting environmental factors that enhance or impede talent development. Rethinking gifted education, 227-238. 